\title{
INFLUENCE OF SUBSTITUTED ELEMENTS ON REFLECTION LOSS OF Ba-FERRITE NANOPARTICLE
}

\begin{abstract}
Due to the rapid development of the information communication industries, it is expected that next-generation mobile communication devices in the data communication environment will be used at the same time in the $\mathrm{L} \sim \mathrm{X}$ band $(1-12 \mathrm{GHz})$. To mutual electric wave interference prevention, research on wave absorbers in $\mathrm{L} \sim \mathrm{X}$ band is needed. In this paper, barium ferrite was researched as $\mathrm{L} \sim \mathrm{X}$ band wave absorber. The Barium ferrite (BaM, Ba ferrite) substituted by divalent ions $\left(\mathrm{Co}^{2+}, \mathrm{Cu}^{2+}, \mathrm{Ni}^{2+}, \mathrm{Zn}^{2+}\right)$ and tetravalent ion $\left(\mathrm{Ti}^{4+}\right)$. The substituted Ba ferrite nanoparticles were fabricated by sol-gel process. Lattice parameter, particle size, magnetic properties, and reflection loss were analyzed by X-ray diffraction (X-RD), a Vibrating Sample Magnetometer (VSM), and a Network Analyzer. Lattice parameter of Ba ferrite was changed 0.0005 to $0.0078 \AA$ in a-b direction, and 0.0187 to $0.0445 \AA$ in c-direction by substituted elements, and it influenced on magnetic anisotropy. In addition, Co-Ti substitution elements influenced that coercive force decrease 5,739 to 2,240 Oe. Moreover, reflection loss frequencies were shifted from $16.3 \mathrm{GHz}$ to 14.4 and 17.4 GHz by substituted elements Co-Ti and $\mathrm{Zn}-\mathrm{Ti}$.

Keywords: Ba ferrite, Substitutional m-type ferrite, reflection loss, sol-gel, additional atom.
\end{abstract}

\section{Introduction}

Due to the rapid development of the Information communication industries, the demanded of information communication device are increasing rapidly. In addition, the frequency distribution has reached its limit, and wave interference between device make devices to malfunctions. Therefore, wave absorber materials are needed in order to eliminate unnecessary frequencies. Ferrite has been widely used as wave absorber material [1]. Ferrite has a different structure and different natural resonance frequency due to its composition and additive elements. $\mathrm{BaFe}_{12} \mathrm{O}_{19}$ has wave absorption band of several gigahertz, as it has high coercive force and high magnetic anisotropy [2] by the $\mathrm{Fe}^{3+}$ ion on the $2 \mathrm{~b}, 4 \mathrm{f}_{2}$ site in its magnetoplumbite structure. Thus, if the $\mathrm{Fe}^{3+}$ ion on the $2 \mathrm{~b}, 4 \mathrm{f}_{2}$ site is substituted by metal ion having a different magnetic moment, the coercive force and magnetic anisotropy of BaM are changed by effect of substituted metal ion. It is known that if $\mathrm{a} \mathrm{Co}^{2+}$ ion were substituted on the $2 \mathrm{~b}$ and $4 \mathrm{f}_{2}$ site, then the coercive force would decrease. The $\mathrm{Fe}^{3+}$ ion must be substituted by a combination of divalent ion $\left(\mathrm{Co}^{2+}, \mathrm{Cu}^{2+}\right.$, $\left.\mathrm{Ni}^{2+}, \mathrm{Zn}^{2+}\right)$ and tetravalent ion $\left(\mathrm{Zr}^{4+}, \mathrm{Sn}^{4+}, \mathrm{Ru}^{4+}, \mathrm{Ti}^{4+}\right)$ according to electronic valence adjustment. The $\mathrm{Ti}^{4+}$ tetravalent ion has an ion radius, $0.605 \AA$ and electronegativity, 1.54 , it is smaller than these of $\mathrm{Fe}^{3+}$ ion. Thus, the $\mathrm{Ti}^{4+}$ ion can be used as a substitute for the $\mathrm{Fe}^{3+}$ ion on the ferrite structure [3-11]. In this study, we investigated wave absorption range change of of $\mathrm{BaFe}_{10} \mathrm{XTiO}_{19}$
(XTiM, $\mathrm{X}=\mathrm{Co}, \mathrm{Cu}, \mathrm{Ni}, \mathrm{Zn}$ ) nanopowder according to change of magnetization easy axis by combination of divalent element (Co, Cu, Ni, Zn) and tetravalent element (Ti). $\mathrm{BaFe}_{10} \mathrm{XTiO}_{19}$ nanopowder was fabricated by sol-gel process. Crystal structure and lattice parameter were examined by X-ray diffraction (XRD), particle size and sharp were examined by SEM, magnetic properties was examined by Vibrating Sample Magnetometer (VSM), and reflection loss was examined by Network Analyzer.

\section{Experimental}

$\mathrm{BaFe}_{12} \mathrm{O}_{19}, \mathrm{BaFe}_{10} \mathrm{XTiO}_{19}(\mathrm{X}=\mathrm{Co}, \mathrm{Cu}, \mathrm{Ni}, \mathrm{Zn})$ nanoparticles were prepared by sol-gel process. Iron nitrate $\left(\mathrm{Fe}\left(\mathrm{NO}_{3}\right)_{3} \cdot 9 \mathrm{H}_{2} \mathrm{O}\right)$, Barium nitrate $\left(\mathrm{Ba}\left(\mathrm{NO}_{3}\right)_{2}\right)$, Cobalt acetate $(\mathrm{Co}(\mathrm{CH} 3 \mathrm{COO}) 2)$, Titanium isopropoxide ( $\left.\mathrm{Ti}\left[\mathrm{OCH}\left(\mathrm{CH}_{3}\right)_{2}\right]_{4}\right)$, Nickel acetate $\left(\mathrm{Ni}\left(\mathrm{CH}_{3} \mathrm{COO}\right)_{2} \cdot \mathrm{XH}_{2} \mathrm{O}\right)$, Zinc acetate $\left(\mathrm{Zn}\left(\mathrm{CH}_{3} \mathrm{COO}\right)_{2} \cdot 2 \mathrm{H}_{2} \mathrm{O}\right)$, and $\mathrm{Cu}$ acetate $\left(\left(\mathrm{CH}_{3} \mathrm{COO}\right)_{2} \mathrm{Cu}\right)$ were used as starting materials. They were mixed by stoichiometric ratio in deionized water (D.I), and then citric acid and ethylene glycol were added to the mixture. Then, the acidity of the mixture was adjusted to $\mathrm{pH} 6$ by an ammonia solution. The mixture was heated and refluxed at $85^{\circ} \mathrm{C}$ for 15 hours until it became a sol. The sol was evaporated at $100^{\circ} \mathrm{C}$ until it was transformed to gel on a hot plate. The gel was annealed in the atmosphere at $900^{\circ} \mathrm{C}$ for 3 hours, and then it was cooled down to room temperature in a furnace.

\footnotetext{
* ADVANCED MATERIALS SCIENCE AND ENGINEERING, INCHEON NATIONAL UNIVERSITY, 119 ACADEMY-RO, YEONSU-GU, INCHEON, 22012 KOREA

** SPIN ENGINEERING PHYSICS TEAM, KOREA BASIC SCIENCE INSTITUTE, DAEJEON, KOREA

\# Corresponding author: jyj309@inu.ac.kr
} 
The crystal structure of the annealed powder was analyzed by $\mathrm{X}-\mathrm{RD}$ (Rigaku, smartLab, $\mathrm{Cu} \mathrm{K} \alpha, \lambda=0.15425 \mathrm{~nm}$ ). Particle size and shape were investigated by SEM (JEOL, JSM-7800F). Saturation magnetization $\left(B_{s}\right)$, Coercive force $\left(H_{c}\right)$, and initial permeability $\left(\mu_{\mathrm{i}}\right)$ were measured by VSM (Quantum Design, VersaLab VSM). Reflection loss was measured by a Network Analyzer (Agilent PNA-X, airline). The sample of reflection loss was prepared as toroidal type with outer diameter $7 \mathrm{~mm}$, inner diameter $3.04 \mathrm{~mm}$, and thickness $1 \mathrm{~mm}$. The mixing ratio of annealed powder and wax was 1:1.

\section{Results and discussion}

$\mathrm{X}-\mathrm{RD}$ peaks of the BaM and XTiM are shown in Fig. 1. Each peak of lattice plane has the same diffraction angle in XRD patterns. This means that the lattice structure of BaM and XTiM are same. The Lattice parameter of the XTiM are shown in Fig. 2. The change of a,b-direction lattice parameter of the XTiM were -0.00049 to $0.00776 \AA$, and the change of c-direction was 0.01875 to $0.04452 \AA$. On average, the change of c-direction lattice parameter was $0.2525 \AA$ greater than that of a,b-direction lattice parameter. This was caused by the radius difference of $\mathrm{Fe}^{3+}$ ion and substituted elements. $\mathrm{Fe}^{3+}$ ion mainly located along the c-axis direction in magnetoplumbite structure [12]. Therefore, the substituted elements had a greater effect on the c-direction lattice parameter than $\mathrm{a}-\mathrm{b}$ direction lattice parameter. SEM images (X 20,000) are shown in Fig. 3. It was confirmed that all samples have particle size of hundreds of nanometer. The magnetic properties of all samples are shown in Fig. 4 and Table 1. It was that saturation magnetization $\left(\mathrm{B}_{\mathrm{s}}\right)$ of the $\mathrm{BaM}$ and $\mathrm{ZnTiM}$ are 46.17 and $51.43 \mathrm{emu} / \mathrm{g}$. By $\mathrm{Zn}$-Ti substitution, saturation magnetization was improved by $5.26 \mathrm{emu} / \mathrm{g}$. The coercive force $\left(\mathrm{H}_{\mathrm{c}}\right)$ of the $\mathrm{BaM}$ and CoTiM are -5739 and -2240 Oe respectively, and the coercive force of Co-Ti substitution was decreased by 3499 Oe. As seen in Table 1, coercive force of the other XTiM shown that

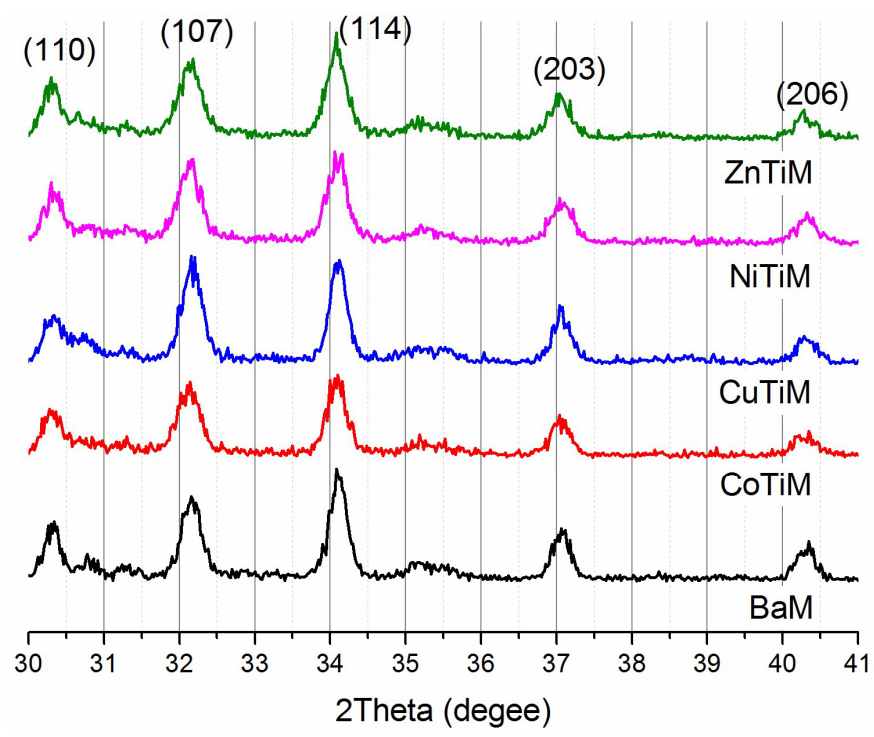

Fig. 1. XRD pattern $\mathrm{BaM}$ and $\mathrm{XTiM}(\mathrm{X}=\mathrm{Co}, \mathrm{Cu}, \mathrm{Ni}, \mathrm{Zn})$
ZnTiM 3,123, NiTiM 3,472, and CuTiM, 4,132 Oe respectively. $\mathrm{Co}^{2+}\left(3 \mu_{\mathrm{b}}\right), \mathrm{Cu}^{2+}\left(1 \mu_{\mathrm{b}}\right)$, and $\mathrm{Ni}^{2+}\left(2 \mu_{\mathrm{b}}\right)$ ions was mainly substituted on $4 \mathrm{f}_{2}$ site [4]. Thus, the coercive force decreases was affected by the magnetic moments of the substitution ions. This results means that the substituted elements influenced the saturation magnetization and the coercive force [3-6].

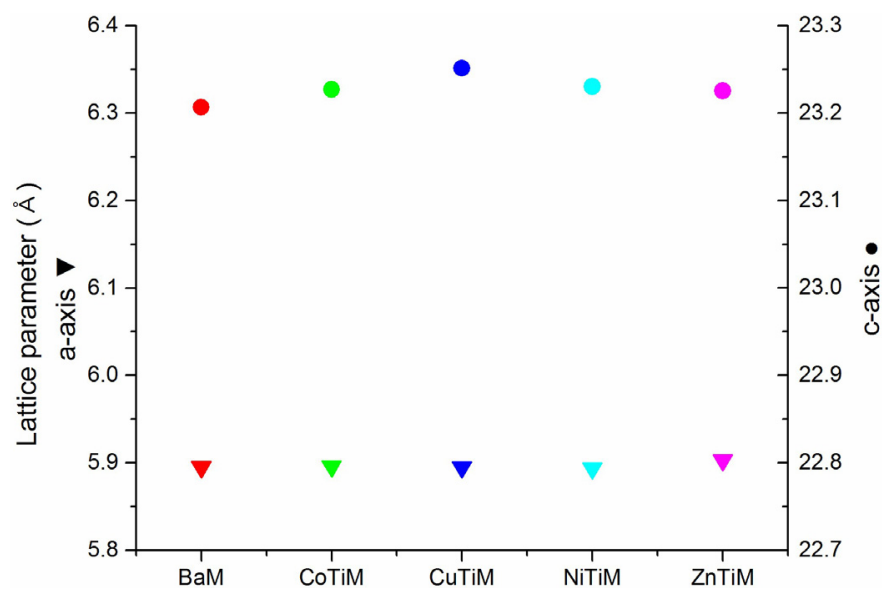

Fig. 2. Lattice parameter of XTiM (X=Co, Cu, Ni, Zn)

TABLE 1

Magnetic properties of $\mathrm{BaM}, \mathrm{XTiM}(\mathrm{X}=\mathrm{Co}, \mathrm{Cu}, \mathrm{Ni}, \mathrm{Zn})$

\begin{tabular}{|c|c|c|c|}
\hline & $\mathbf{B}_{\mathbf{s}}(\mathbf{e m u} / \mathbf{g})$ & $\mathbf{H}_{\mathbf{c}}(\mathbf{O e})$ & $\boldsymbol{\mu}_{\mathbf{i}}$ \\
\hline BaM & 46.17 & -5739 & 0.00249 \\
\hline CoTiM & 47.87 & -2240 & 0.00539 \\
\hline CuTiM & 45.23 & -4132 & 0.00393 \\
\hline NiTiM & 43.73 & -3471 & 0.00325 \\
\hline ZnTiM & 51.43 & -3123 & 0.00216 \\
\hline
\end{tabular}

The reflection loss of XTiM is shown in Fig. 5. The natural resonance frequencies of BaM, CoTiM, CuTiM, NiTiM, and ZnTiM were 16.3, 14.4, 16.8, 17.2, and $17.4 \mathrm{GHz}$, respectively. The natural resonance frequency of CoTiM was shifted down 16.3 to $14.4 \mathrm{GHz}$, it was affected by coercive force decrease. However, the natural resonance frequencies of XTiM with $\mathrm{Cu}$, $\mathrm{Ni}$, and $\mathrm{Zn}$ were shifted up. The natural resonance frequency increase of substituted CuTiM and NiTiM were affected by the lattice parameter increase of c-axis direction. In addition, the natural resonance frequency increase of the ZnTiM was affected by saturation magnetization increase 46.17 to 51.43 $\mathrm{emu} / \mathrm{g}[13,14]$.

\section{Conclusions}

In order to shift natural resonance frequency of BaM with $\mathrm{L} \sim \mathrm{X}$ band, $\mathrm{Fe}^{3+}$ ion located at $2 \mathrm{~b}$ and $4 \mathrm{f}_{2}$ in magnetoplumbite structure was substituted by combination of divalent ion $\left(\mathrm{Co}^{2+}\right.$, $\left.\mathrm{Cu}^{2+}, \mathrm{Ni}^{2+}, \mathrm{Zn}^{2+}\right)$ and tetravalent ion $\left(\mathrm{Ti}^{4+}\right)$. The natural resonance frequency of CoTiM was shifted down $16.3 \mathrm{GHz}$ of BaM to $14.4 \mathrm{GHz}$. It was caused that coercive force of CoTiM had -2240 Oe, lower than that of BaM. However, the natural reso- 


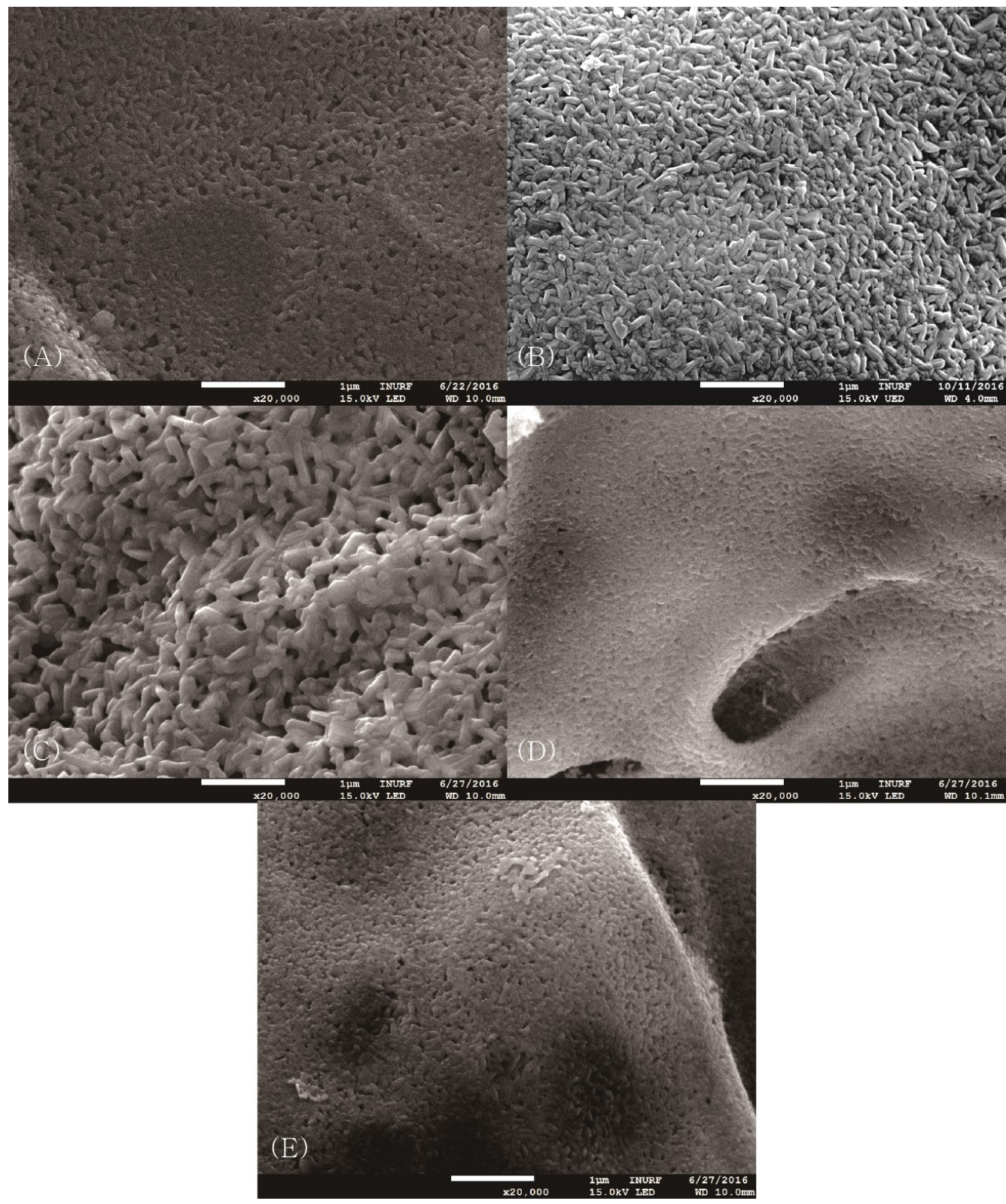

Fig. 3. SEM image X20,000 (a) BaM, (b) CoTiM, (c) CuTiM, (d) NiTiM, (e) ZnTiM

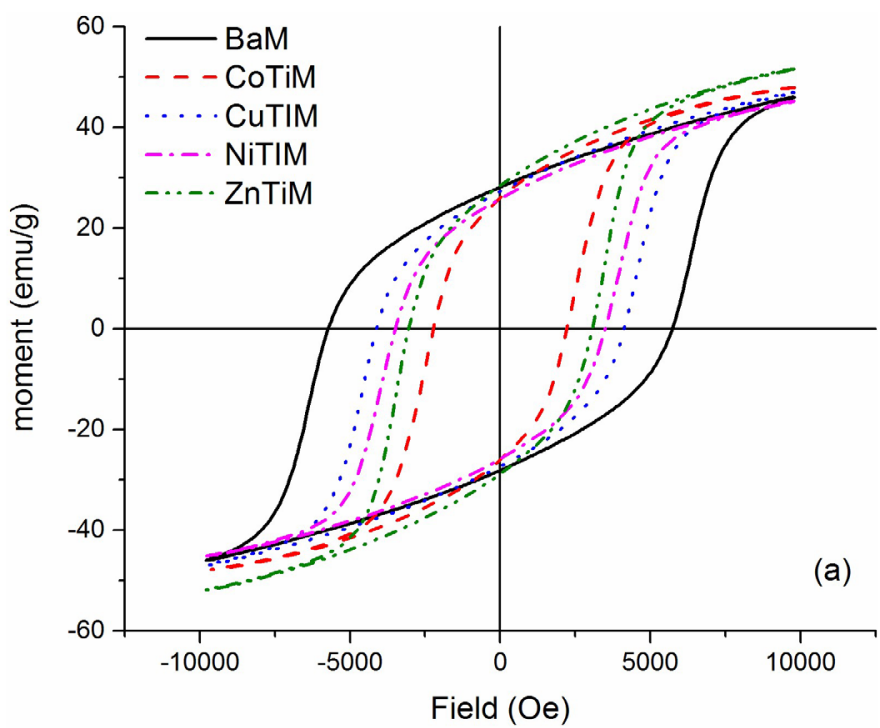

Fig. 4. B-H hysteresis loop of $\mathrm{BaM}$ and $\mathrm{XTiM}(\mathrm{X}=\mathrm{Co}, \mathrm{Cu}, \mathrm{Ni}, \mathrm{Zn})$

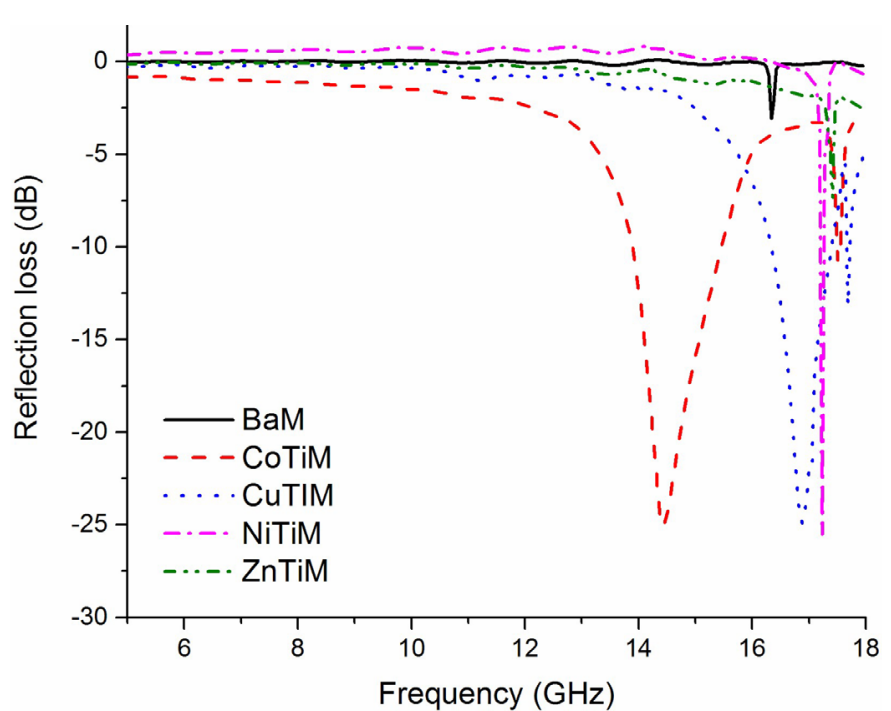

Fig. 5. Reflection loss $\mathrm{BaM}$ and $\mathrm{XTiM}(\mathrm{X}=\mathrm{Co}, \mathrm{Cu}, \mathrm{Ni}, \mathrm{Zn})$ 
nance frequency of CuTiM, NiTiM, and ZnTiM were shifted up to $16.8,17.2$, and $17.4 \mathrm{GHz}$, respectively. It was caused by increase of magnetic anisotropy and saturation magnetization. It was confirmed that the decrease of coercive force of CoTiM made natural resonance frequency to lower frequency $14.4 \mathrm{GHz}$ than $16.3 \mathrm{GHz}$ of BaM.

\section{Acknowledgments}

This work was supported by the National Research Council of Science \& Technology (NST) grant (No. CAP-16-01-KIST) by the Korea government (MSIP)

\section{REFERENCES}

[1] Y. Naito, K. Suetake, IEEE. T. Microw, Theory. MTT-19, 65-72 (1971).

[2] M. Mohebbi, K. Ebnabbasi, C. Vittoria, IEEE. T. Magn. 49, 42074209 (2013).

[3] T. Tsutaoka, N. Koga, J. Magn. Magn. Mater. 325, 36-41 (2013).
[4] S. Kanagesan, S. Jesurani, R. Velmurugan, T. Kalaivani, J. Mater. Sci-Mater. El. 23, 952-925 (2012)

[5] L. Jia, H. Zhang, S. Yin, F. Bai, B. Liu, Q. Wen, J. Shen, J. Appl. Phys. 109, 07E317-1-07E317-3 (2011).

[6] C. Li, B. Huang, J. Wang, J. Mater. Sci. 48, 1702-1710 (2013).

[7] H.M. Khan, M.U. Islam, Y. Xu, M.A. Iqbal, I. Ali, J. Alloys Compd. 589, 258-262 (2014)

[8] S.K. Chawla, R.K. Mudsainiyan, S.S. Meena, S.M. Yusuf, J. Magn. Magn. Mater. 350, 23-29 (2014)

[9] Z.F. Zi, Q.C. Liu, J.M. Dai, Y.P. Sun, Solid. State. Commun. 152, 894-897(2012).

[10] E.D. Solovéva, E.V. Pashkova, A.E. Perekos, A.G. Belous, Inorg. Mater. 48, 1147-1152 (2012).

[11] C. Singh, S.B. Narang, I.S. Hudiara, Y. Bai, F. Tabatabaei, Mater. Res. Bull. 43, 176-184 (2008).

[12] L.S.I. Liyanage, S. Kim, Y. Hong, J. Park, S.C. Erwin, Cond-mat. Mtrl-sci, 1209.5143v2 (2013).

[13] J. Smit, H.P.J. Wijn, Philips Technical Library, Ferrites, London, 1959.

[14] E.P. Wohlfarth, North-Holland Pub, Ferromagnetic Materials 3, Amsterdam (1982). 